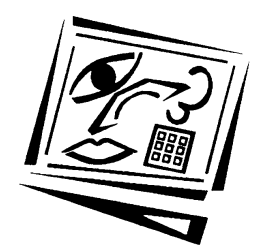

\title{
Learning as students to become better teachers: Pre-service teachers' IWB learning experience
}

\author{
Shanti Divaharan and Joyce Hwee Ling Koh \\ Nanyang Technological University
}

\begin{abstract}
The study presented in this paper involved 124 Singaporean pre-service teachers who were attending a core information and communications technology (ICT) module, which is a component of their teacher education program. During this module, the pre-service teachers were introduced to the interactive whiteboard (IWB) through an instructional approach that consisted of tutor modeling, self-paced exploration, peer sharing, and team-based design projects. The pre-service teachers experienced the IWB first as 'students' and then explored it as teachers planning for implementation in their lessons. Qualitative data of pre-service teachers' reflections was collected to analyse their perceptions of the IWB use in their lessons and to examine how they learnt to use the board. The findings illustrated that pre-service teachers predominantly felt that the IWB was useful for engaging students in the learning process and for generating active participation vis-à-vis the interactive affordances of the board. The findings also revealed that learning about technology in teams was most useful for the successful assimilation of a technology tool that was new and unfamiliar to pre-service teachers. This paper examines how the existing IWB instructional approach can be modified to help pre-service teachers learn pedagogical uses of the IWB more effectively.
\end{abstract}

\section{Introduction}

Much research on the interactive whiteboard (IWB) has been conducted in the United Kingdom (Gillen, Staarman, Littleton, Mercer \& Twiner, 2007; Kennewell \& Beauchamp, 2007), New Zealand (Hodge \& Anderson, 2007), recently in Australia (Holmes, 2009) and United States of America (López, 2010). A number of these studies focused on how teachers were using the IWB in their lessons (Hodge \& Anderson, 2007; Wood \& Ashfield, 2008). Some studies researched the various features of the IWB and how it impacted teaching and learning (Haldane, 2007; Jewitt, Moss, \& Cardini, 2007). Other studies document the introduction of IWB in pre-service teacher education (Beyerbach, Walsh, \& Vannatta, 2001; Holmes, 2009).

This study documents the attempt of a teacher education institute in Singapore to implement the use of the IWB in its core information and communication technology (ICT) module. Research has shown that teachers find using the IWB easier than integrating other forms of technology (Smith, Higgins, Wall, \& Miller, 2005). The researchers, who were also tutors for the groups, introduced the basic features of the board by demonstrating the functions of the features during the course of their teaching. This captured the attention of the pre-service teachers as they were amazed by the flexibility and interactivity of the medium. The focus of this paper is to present the perceptions of Singapore pre-service teachers' on how the IWB can be used in their classrooms for teaching and learning. In addition, the paper will describe the IWB 
instructional approach used, and examine the factors that facilitated the learning of this new technology within the ICT course. The effectiveness of the IWB instructional approach will be examined and future modifications of the IWB curriculum in preservice teacher training will be discussed.

\section{Research on interactive whiteboards}

\section{Perceptions of the IWB by teachers}

The affordances of the IWB and how they can be harnessed to engage students in the classroom have been well researched (Haldane, 2007; Kennewell \& Beauchamp, 2007). The IWB provides opportunities for teachers to present concepts in a textual, audio and visual manner, which can be used to cater to students with different learning styles. Research findings propose that teachers should harness this multimodality affordance of the IWB to facilitate students' learning (Ball, 2003; Jewitt et al., 2007; Kennewell \& Beauchamp, 2007). However, others caution that teachers should not be carried away by the multimodality aspect which may distract them to focus too much on its resources, rather than on students' learning (Solvie, 2004).

Studies conducted by Coupal (2004) and Polyzou (2005) are in agreement that teachers favour the use of the IWB because of its ability to provide 'hands on' experience to students. Jewitt et al. (2007) suggest that interactivity can be categorised into technical interactivity, physical interactivity and conceptual interactivity. The IWBs are effective for increasing students' level of involvement in the lessons (Ball, 2003; Miller, 2003). While the IWB templates and resources inherently capture attention (Kennewell, 2005), it is important to note that teachers are the designers of the lesson and hence they also need to be equipped with the relevant skills to make pedagogically sound use of the IWB (Knight, Pennant \& Piggott, 2004).

\section{Professional development for teachers to integrate ICT}

Research conducted in the area of general ICT integration in the classrooms reveal that teachers were seen rooted in the traditional instructional form and hence they were not making the necessary effort to integrate ICTs to create innovative learning experiences for their students (Demetriadis et al., 2003; Soetaert \& van Belle, 2001). Teachers need knowledge of appropriate ICT integration strategies and ICT skills to integrate ICT in ways that optimise the benefits for their students' learning (Pierson, 2001; Shuldman, 2004). Teachers' professional development needs to focus on both ICT skills training as well as appropriate ICT integration strategies in the curriculum.

Chu (2000) conducted a research study focusing on teachers' stages of concerns about ICT knowledge as well as use of ICT in the classrooms. Chu used the 'Computing Concerns Questionnaire and Teaching with Technology Survey' to gather data. The findings of this study indicated that the level of technology confidence was positively correlated to higher use of ICT in the classrooms. Braak (2001) also conducted a study with the aim of investigating the relationship between computer use in the classroom and influencing factors on an individual level. His random sample of 236 secondary school teachers in Brussels indicated that teachers' high level of confidence in using ICT revealed that they were more inclined to change teaching through the use of technology in their classrooms. However, Braak suggested that to overcome the lack of translation of ICT competency and comfort level into strategies for applying ICT 
effectively, there was a need to expose teachers to good practices during in-service training. The focus of this training should be to get teachers familiarised with ICT, on the use of ICT as well as the value of ICT as a pedagogical tool.

From the findings reported, it is evident that effective use of computers is dependent on the teachers' ICT skills as well as their intention of ICT use (Albalat \& Tarrago, 1995; Hodgson, 1995; Venezky, 2004). Relevant professional development can take the form of observing colleagues, learning from each other, observation of each others' ICT-integrated lessons, as well as to provide opportunities for teachers to share and collaborate with each other (Blase \& Blase, 1999; Flanagan \& Jacobsen, 2003; Jacobsen, 2001, 2002; Prain \& Hand, 2003). In fact, Jaber and Moore's (1999) findings revealed that teachers preferred continuous rather than one-off training, and they learnt more from sharing with their peers. Teachers also preferred if training focused on pedagogical use of technology. Teachers can be exposed to various ICT integration approaches through exchanges among colleagues and attending conferences, as well as observing each other's classroom practices.

The findings from these studies indicated that attention must be given to professional development for teachers if schools want to see success in effective ICT integration in the curriculum. Findings by other studies on the obstacles to effective ICT integration suggested lack of training as one of the reasons (Ertmer, 1999; Manternach-Wigans, 1999; Martin, 2000; Wang \& Chan, 1995). Therefore, it might make a significant difference for ICT integration in schools if attention is given to ensure teachers are given opportunities to attend relevant professional development.

Research about professional development in IWB for teachers has been conducted. One such longitudinal study of professional development for 22 mathematics teachers was conducted in the United Kingdom. The study found that effective professional development for teachers together with specific personal coaching was needed to improve the teachers' pedagogical approach to implementing the IWB in their lessons (Miller \& Glover, 2007). Another study which examined a national initiative to train all teachers in England, placed emphasis on how teachers should be trained (Davis, Preston, \& Sahin, 2009). The study applied a framework by Guskey (2002) to evaluate professional development for teachers. The results of the study support an ecological view to the training of teachers and to establish a community of practice to support the continued development of teachers. A self-study methodology applied to explore a teacher's journey in a primary school in Auckland reinforced these findings. In this study, the teachers were able to focus on exploring various pedagogies associated with the use of the IWB after they had overcome issues with technical skills (Hodge \& Anderson, 2007). As Haldane (2007) aptly says it:

It is the user of the board who chooses whether or not to take full advantage of the digital whiteboard's interactive potential. The digital board ... (is) not the creator of the message nor the one to decide how the messages will be conveyed. (p. 259)

Most of these studies have focused on the professional development of in-service teachers. There is a need to examine how pre-service teachers' learning should be designed so that they know how to effectively design IWB integrated lessons for their students. As the IWB becomes increasingly used in schools, it is important that they have adequate preparation for using the IWB during teacher education. Pre-service teachers who are familiar with the IWB, its potential and its limitations can make informed decisions when they plan and practise their lesson during their training 
(Holmes, 2009). Pre-service teachers are relatively unfamiliar with teaching practices. The methods for teaching them about pedagogical uses of the IWB could be slightly different than those for in-service teachers. There is substantial evidence that faculty modeling of technology use is a particularly successful strategy for pre-service technology integration training (Strudler \& Wetzel, 1999; Beyerbach, Walsh \& Vannatta, 2001; Pope, Hare \& Howard, 2002; Brush, Glazewiski, Rutowiski, Berg, Stromfors, Stock \& Stutton, 2003). Handler (1993) found that those who frequently saw computers being used in their pre-service methods course felt better prepared to use the computer as an instructional tool. When faculty modeling is followed by opportunities for them to practice and apply technology tools in the preparation of instructional tasks, it increased their self reported confidence level for utilising these technologies in the classroom (Pope et al., 2002). Pellegrino and Altman (1997) commented that application and design activities allowed them to encounter the complex decisions for applying technology to their own teaching, which facilitates their transfer of technology knowledge into classroom application.

A comparison of both in-service and pre-service professional development methods reveals that the technical skills need to be addressed. During in-service teacher professional development, exposing teachers to possible pedagogical approaches seems to enable them to plan and conduct effective technology tool integrated lessons. In pre-service training, however, there seems to be a need for tutor modeling of the tool so as to allow pre-service teachers to experience the tool before they are comfortable with designing lessons that integrate the tool.

This study addresses the gap in IWB research on pre-service teachers by examining Singapore's pre-service teachers' perceptions of the IWB, and the processes they adopted to learn it. The research questions are as follows:

1. What are Singapore pre-service teachers' perceptions of how the IWB can be implemented in their classrooms for teaching and learning?

2. What are the factors that supported these pre-service teachers to learn the IWB?

3. What is an effective approach for teaching the pedagogical uses of the IWB?

\section{Method}

\section{Course context}

The study was conducted with 124 pre-service teachers who were attending a 12-week core ICT course that trains them in pedagogical skills associated with ICT integration in their subject area. Pre-service teachers were taught the theories and principles of technology integration during the first five weeks. The next seven weeks were devoted to technology integration modules which focused on the pedagogical use of specific technology tools. As tutorial groups were formed by subject specialisation, tutors and pre-service teachers in each tutorial group jointly selected two or three technology integration modules that were pertinent to the group. Examples of technology integration modules available for selection were the IWB, concept mapping, educational games, webquests, and Web 2.0 tools such as wikis and blogs. This study was conducted across a three-week period where pre-service teachers were learning how to use the IWB as a technology integration module. This technology integration module consisted of three two-hour lessons where one lesson was conducted each week. 


\section{The IWB technology integration module}

This study was conducted during the July 2009 semester when the IWB technology integration module was introduced for the first time within the ICT course. Five tutorial groups who opted for the IWB technology integration module were randomly selected for this study. Three of the tutorial groups were from the Diploma in Education cohort and they were trained to teach primary school students. These 74 pre-service teachers were being trained to teach a range of subjects such as English, mathematics, science, social studies and second languages (Chinese and Malay languages). Two other tutorial groups were from the Post Graduate Diploma in Education Secondary programme. These 50 pre-service teachers were secondary school teachers majoring in mathematics, chemistry, history and English language.

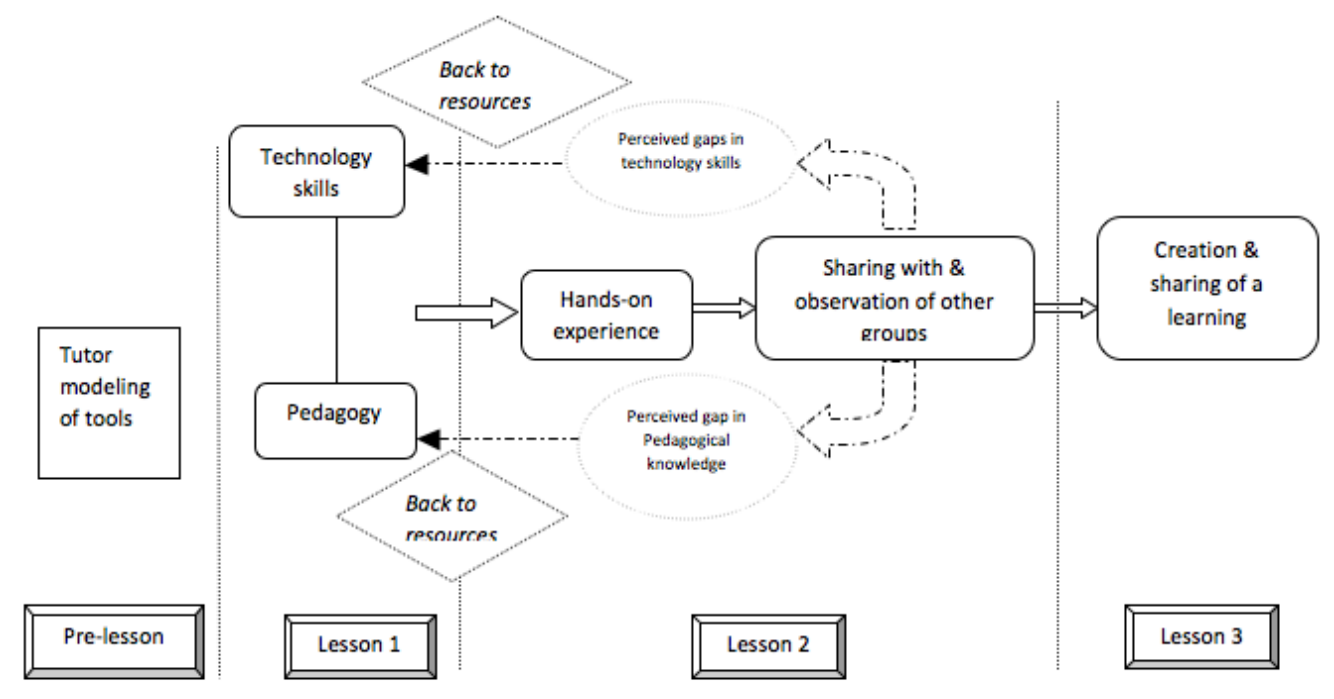

Figure 1: Approach to the IWB technology learning component

Tutors in these tutorial groups asked pre-service teachers about their prior experiences with the IWB. For these tutorial groups, the majority of the pre-service teachers had no prior exposure for the IWB, which was why they indicated a strong interest in selecting the IWB as one of the technology tools that they would like to learn.

The IWB technology integration module was then conducted for these classes across three two-hour tutorial sessions. These three lessons were designed based on a literature review of professional development models for teachers when learning new technology tools (see Figure 1).

\section{Pre-lesson: Tutor modeling of tools}

Prior to Lesson 1, the tutor had made attempts to demonstrate basic features of the IWB as part of their normal teaching (refer to Figure 1). This was a part of tutor modeling. Examples of features demonstrated were pen, eraser, highlighter, drag and drop, magnifier and spotlight. 


\section{Lesson 1: Self-paced learning from technological resources and pedagogical examples}

During Lesson 1, the tutor re-capitulated these features, and clarified doubts. Preservice teachers then accessed an online, self paced tutorial (see Figure 2) which pointed them to various resources about the IWB. They were free to explore the various the IWB resources independently or in their pre-assigned subject specialisation teams during Lesson 1.

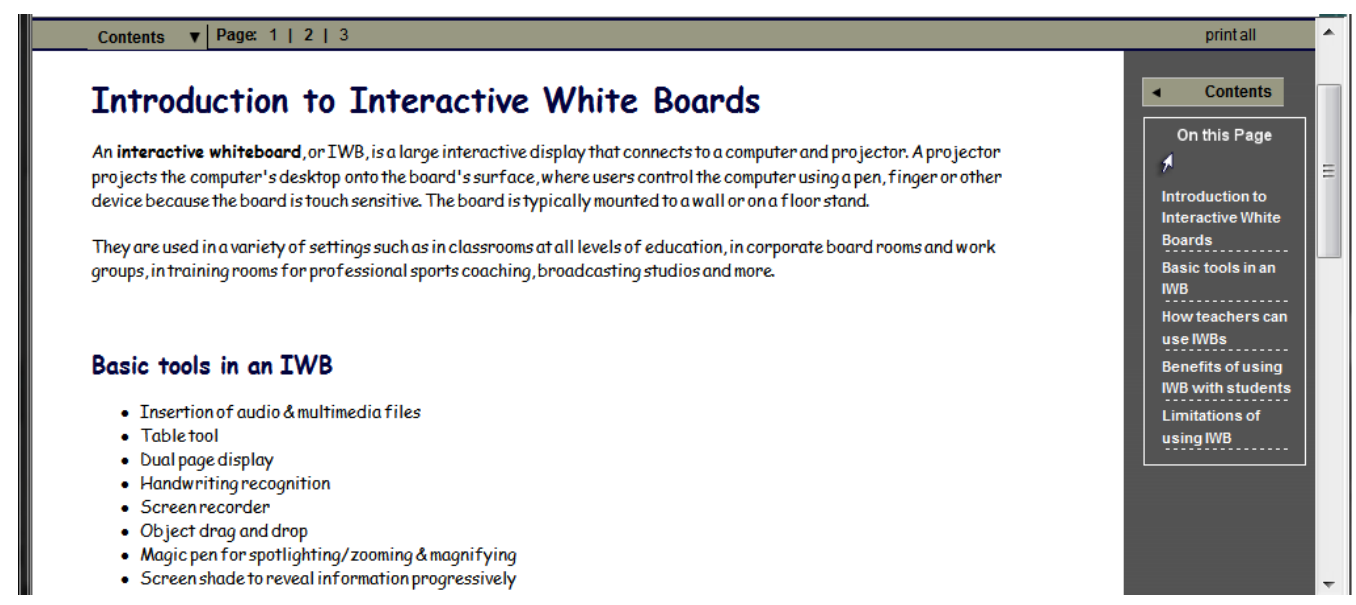

Figure 2: Self paced tutorial

Pre-service teachers were also given access to video-based resources that demonstrated how the various tools of the IWB functioned (for example, see Figure 3). These resources supported pre-service teachers to build their technical skills for use of the IWB.
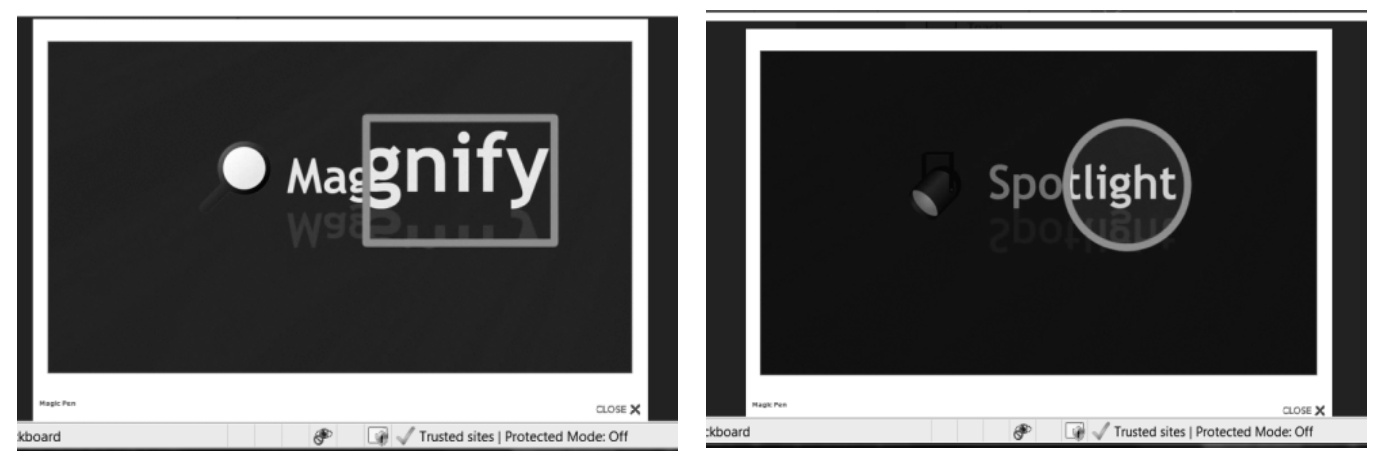

Figure 3: Screen captures of video-based, self learning tutorials

Pre-service teachers were also asked to explore a database of lesson templates and materials for the IWB that were prepared by teachers from Canada, United Kingdom and America. Since Singapore teachers are not yet actively involved in the use of the IWB and sharing the content they have created, the researchers had to rely on a database created by teachers from other countries for a start. This was to create awareness of the pedagogical approaches adopted by teachers when they utilise the 
IWB in their lesson. It was also a form of pedagogical modeling, in addition to that by the tutor.

\section{Lesson 2: Hands on exploration and peer sharing}

The objective of Lesson 2 was to help pre-service teachers generate ideas for using the IWB through hands on exploration and peer sharing. Pre-service teachers formed groups based on their pre-assigned subject specialisation teams, and shared their ideas for using the IWB ideas with team members during the first half of the lesson. Each team could also experiment and apply these ideas by working with the IWB board during this time. During the second half of the lesson, each team shared a particular feature that they had learnt, and showcased a classroom application to the rest in the tutorial group. The intention of this activity was to expose the pre-service teachers to a range of potential applications of a feature which they had not thought of. These activities also helped pre-service teachers to pinpoint their personal gaps in terms of technological skills and pedagogical knowledge. At the end of this lesson, they were asked to review the video-based tutorials and the lesson database for areas they were unsure of, in preparation for the next lesson.

\section{Lesson 3: Application to content area in teams}

The aim of this lesson was to help pre-service teachers relate their content specialisation to the use of the IWB. Pre-service teaches worked in the same teams as in Lesson 2. Each team was tasked to select an area from their content specialisation and create a learning/teaching component using the IWB features which they had learnt. This was to provide hands on design experiences.

There was no attempt to teach content knowledge during the ICT course as they were already attending methods courses for their subject specialisations.

\section{Data collection}

This study adopted a design-based approach which is characterised by iterative development-testing-revision cycles in which instructional processes or products are continuously improved toward their intended objective of use (Lesh, Kelly \& Yoon, 2008). This is the first of a series of reviews which the authors intend to adopt in order to enhance the learning experience of pre-service teachers' when they learn a new technology tool. After this stage of reviewing the findings, the authors will modify the pedagogical approach for pre-service teachers' learning. To understand how preservice teachers' learnt to use the IWB and the factors that encouraged or inhibited their learning, they were given 30 minutes to do a reflection in their subject teams at the end of Lessons 1 and 2. The 124 teachers were divided into 30 subject teams, each comprising four to five members. Each subject team posted their reflections on their wiki page that was set-up for them before the module. Therefore, two sets of reflections were collected from each team. During the course of the two lessons, tutors also took observation notes on how the groups interacted and their learning preferences.

During each reflection, pre-service teachers posted responses for the following questions:

1. How do you think you can use the IWB tool/software in your classroom? 
2. What are the pros/cons of this tool/software in supporting meaningful learning?

3. What difficulties did you face when learning the IWB tool/software?

4. How did you overcome the difficulties?

5. How did you and your team members learn the IWB tool/software? Describe your individual experiences.

These reflections allowed the researchers to determine whether the approach outlined in Figure 1 was successful.

\section{Data analysis}

Data was analysed through content analysis of pre-service teachers' reflections. The first author coded the following reflection questions to derive answers for the research questions as follows:

a. Research question 1 - Pre-service teachers' perceptions of how the IWB can be used: Reflection questions 1 and 2.

b. Research question 2 - Factors supporting pre-service teachers to learn the IWB: Reflection questions 3,4 and 5.

c. Research question 3 - Effective approach for teaching the pedagogical use of the IWB: Reflection questions 3, 4 and 5.

The second author (a tutor of participating tutorial groups), verified the codes with respect to her observations of student behaviour during the IWB technology integration module.

\section{Results}

Research question 1 - What are pre-service teachers' perceptions of how the IWB can be implemented in their classrooms for teaching and learning?

Table 1: Different pedagogical uses pre-service teachers perceived of the IWB

\begin{tabular}{|c|c|c|c|}
\hline \multicolumn{2}{|r|}{ Use } & $\begin{array}{l}\text { No. of } \\
\text { teams }\end{array}$ & $\begin{array}{c}\% \text { of } \\
\text { teams }\end{array}$ \\
\hline \multirow{4}{*}{$\begin{array}{l}\text { Frontal } \\
\text { teaching }\end{array}$} & 1. For content presentation during frontal teaching & 21 & 69 \\
\hline & 2. Attract students' attention during frontal teaching & 26 & 87 \\
\hline & 3. Stimulate enthusiasm and excitement during frontal teaching & 19 & 63 \\
\hline & 4. Engage participation through games during frontal teaching & 9 & 36 \\
\hline \multicolumn{2}{|c|}{ Support evaluation of students' learning } & 25 & 83 \\
\hline \multicolumn{2}{|c|}{ Support student centred learning } & 9 & 36 \\
\hline \multicolumn{2}{|c|}{ Support teacher planning of lessons } & 17 & 56 \\
\hline
\end{tabular}

\section{Frontal teaching}

Pre-service teachers perceived different ways where the IWB could be used to support frontal teaching. As can be see from Table 1, about $69 \%$ of the teams $(n=21)$ felt that the IWB was a convenient way for presenting teaching and learning materials to their students. The reasons cited ranged from ready to use templates, graphics, interactive resources and access to the Internet:

It is colourful and we can use the ready-made templates. We can also add in pictures and it is very flexible. It is user-friendly... 
Using the IWB to support frontal teaching can make learning active and interactive. This can be carried out through the use of features such as drag and drop, highlight, write and erase.

I can also get my students to go up to the board and highlight important words, drag and drop boxes. It is very interactive!!

Close to $87 \%$ of the teams $(n=26)$ thought that the IWB was a useful technology to attract students' attention during lessons. They considered it as an integrated platform that allowed them to weave together multiple modes of learning resources, which will be visually appealing to the students:

There is a complete platform because pictures, graphs and texts can be incorporated into one lesson ...

We can use the IWB as a video player, which is good for introductory purposes. We can embed external Flash files and pictures ...

More than half the teams ( $n=19)$ also felt that the IWB can help them stimulate enthusiasm and excitement during class, thereby encouraging participation especially from those who seldom contribute:

I can use this (IWB) to increase the students' enthusiasm and interest to learn something new

$36 \%$ of the teams $(n=9)$ also felt that the interactive nature of the board will allow them to play games with students, giving them more opportunities for participation as compared to just using the computer and projection screen.

\section{Evaluation of learning}

Pre-service teachers also perceived the IWB to be a useful platform for monitoring students' understanding, and evaluating their learning $(\mathrm{n}=25)$ :

During (whole class) evaluation ... IWB can be used a platform to replace verbal assessment ...

Design quizzes, checking on students' understanding while conducting lessons ...

(The platform) ... can be used to assess student's basic understanding of the topic.

To portray common mistakes made by peers, so that they are able to learn from each other ... to test for understanding of students on a new topic.

They felt that it was a non-threatening and informal mode of assessing students' learning:

If students make mistakes, they realise their mistakes in a more light-hearted manner ... (through funny sound effects and graphics)

\section{Student centred learning}

Besides teacher directed uses such as frontal teaching and evaluation, pre-service teachers also noted some ways where the IWB can be used to support student centred learning. For example, $36 \%$ of the teams $(n=9)$ proposed that it can be used as a platform to help students to create and visualise mind maps. This mind map can be re- 
visited, refined and shared with the students so that they can continue to develop it on their own.

However, they also noted some limitations of the IWB. About $94 \%$ of the teams $(\mathrm{n}=$ 29) agreed that the board only processed one touch input at any point in time. Opportunities to use it for collaborative learning was therefore curtailed:

Does not support collaborative learning ... not everyone can take part at the same time.

\section{Teaching process}

Pre-service teachers also reflected on how the use of the IWB can support the teaching process. They felt that planning and creating lessons using the IWB will be convenient and will enable them to refine the lesson easily to improve it (56\% of the teams). The also believed that they can easily adapt the materials to suit the needs of students with different learning abilities:

Also it is very easy for the teacher to create and edit templates almost immediately.

Can be stored, shared and retrieved easily on a school database to allow sharing of resources.

But, they also raised several classroom management issues associated with using the IWB. One was cost (25\% of the teams). They perceived the IWB to be an expensive platform, and it was difficult to have one in every classroom. The pre-service teachers were also worried about what they will do in the event of a power failure (31\% of the teams).

\section{Discussion}

From the responses of the teams, it can be deduced that the pre-service teachers did see value in the use of the IWB as a platform in the classroom. In addition to engaging their learners, they were of the opinion that it provided ample opportunities for students to participate actively. They also appreciated the affordance of the platform where they could integrate various modes of resources, thus allowing them to cater to the various learning styles and needs of their students. These results generally supported the findings of Ball (2003), Miller (2003), Coupal (2004) and Polyzou (2005). Interesting perspectives that emerged from this study included the use of the IWB for monitoring their students' understanding and to evaluate them in an informal manner for continuous learning to take place, as well as its ease of use with respect to teaching processes. In summary, Singapore pre-service teachers in this research perceived the IWB to be useful for making frontal teaching more engaging and participative. However, its key limitation, they perceived, was its inadequacy for supporting collaborative learning.

Table 2: Research question 2.

What are the factors that supported these pre-service teachers to learn the IWB?

\begin{tabular}{|l|c|c|}
\hline \multicolumn{1}{|c|}{ Factor } & No. of teams & $\%$ of teams \\
\hline Hands on exploration & 29 & 96 \\
\hline Self-paced learning tutorial and video resources & 9 & 30 \\
\hline Tutor modeling & 20 & 66 \\
\hline Peer sharing & 20 & 63 \\
\hline Learning in teams & 28 & 93 \\
\hline
\end{tabular}




\section{Hands on exploration}

$96 \%$ of the teams $(n=29)$ indicated that opportunities for hands on practice and self exploration were useful for helping them learn the IWB:

By playing with it for a while, I find that it's interactive and I'm sure this will arouse the kid's interest greatly.

Clicked on everything to see what it was all about ... Explored the various functions available to us ... Tried a few activities to decide which we wanted.

\section{Resources}

Some teams $(\mathrm{n}=9)$ also found the resources given to them to study before hands on exploration to be useful. But they still felt that hands on exploration gave them good opportunity to familiarise themselves with the board and software:

Reading up in advance about the IWB. Through examples given by the tutor and hands on practices. We need to try out the features in the IWB to familiarise ourselves with the tools we can use.

Try out the different templates ... we also viewed sample activities to improve on our lessons ... downloaded the software to play around at home.

\section{Tutor modeling}

About $66 \%$ of the teams $(n=20)$ reflected that their attention and interest to learn the IWB began with them observing tutor usage and demonstration of the technology when she taught her normal lessons.

The tutor demonstrated the use of the IWB and I find it very interesting because I have never used it before. And I thought it would be useful and interesting to be used in the classroom.

(We) observed the tutor using the IWB and were amazed by the technology and the different features of the IWB.

\section{Peer sharing}

The teams believed that observing other teams sharing their knowledge helped them to learn features and pedagogies that they might have overlooked or had not thought of. About $63 \%$ of the teams $(n=20)$ highlighted that they benefitted from other teams' presentations and sharing:

The other teams' presentation helped expose me to various other types of activities.

Also, we also learnt more about the IWB from other teams' products.

That there were more activities and we saw how other teams made use of them in different ways. (e.g. inserting a video)

\section{Learning in teams}

Team learning also featured highly in their reflections. Almost all of the teams $(\mathrm{n}=28)$ shared in their reflections that learning with their teammates helped them to learn a new technology: 
Some teams explored and learnt together.

Each of us try out different templates and show teams members what we have.

When we tried on a specific template, we will discuss if it's appropriate for our activity. One of us searched for the content and the other will try to master the functions.

There were more ideas generated, since it was done in a team. We could instantly decide if the activity was effective.

Other teams adopted a collaborative learning approach where they each learnt something different and then they came together to share with their team mates and to learn from each other.

we explored the entire software on our own, before coming together to decide on the better ones to use for the activity.... We showed each other the new things we found and how we could apply it to our activity.

We divided our learning task by giving each other different roles to play. We browsed through different examples to select the appropriate examples which are best suited for our topic. We ensured that one of us keep each other on task (Morale Booster). We also discussed about the questions that we would like to ask our students.

It was some form of a JIGSAW process whereby every individual are experts at eliciting understanding from (our tutor's) presentation. Following which, we compiled our ideas and collaborated in creating the awesome IWB lesson that impressed many.

Each one of us just experimented on our own and share some of our findings collectively.

\section{Summary of findings}

From the teams' reflections, a few key factors emerged. The teams appreciated the resources that were provided to them on how the features of the board worked. They also managed to gather ideas of the related pedagogies that they can apply while using the IWB for their lessons from tutor modeling. After exploring the resources, the teams welcomed the opportunity for hands on exploration time where they further worked together as a team and learnt through trial and error. These results supported the findings of extant research where faculty modeling (Beyerbach et al., 2001; Pope, Hare \& Howard, 2005; Strudler \& Wetzel, 1999) was found to be most influential in raising pre-service teachers' self efficacy for technology use. A combination of skills and exposure to various pedagogies helped them to plan for their own sharing session when they had to present how they will utilise the IWB for a learning component for their students. This concurred with Pellegrino and Altman (1997), Bayerbach, Walsh and Vannatta (2001) and Snider (2002), who found that when pre-service teachers had hands on practice in developing technology integrated lessons, it made them more amenable to using new technology.

Interesting, opportunities for collaborative learning played an important role in helping pre-service teachers gain acceptance for a new technology tool. In this study, the teams did not have to learn the technology by themselves. Rather, they worked with team members who were teaching the same subject area. This team effort seemed to benefit them since they could explore and learn together. When in doubt, there were team members they could count on to help them to overcome their difficulties. 
Creating opportunities for the teams to learn from each other, by encouraging a culture of sharing also opened up more learning opportunities than could have been possible if they had just learnt within their teams. The teams noted in their reflections that they learnt from other teams how the same features can be implemented in various manners. They discovered that there were other pedagogical approaches besides what their own team members had thought of. This culture of sharing enabled them to acquire a wide repertoire of pedagogical approaches for use in their subject areas.

\section{Research question 3: What is an effective approach for teaching the pedagogical uses of the IWB?}

The pre-service teachers' reflections highlighted that there were some factors that needed to be considered in order to make the learning of the new tool effective. However, analysis of the difficulties they faced during the learning process provided inputs by which our approach to IWB instruction could be improved.

Despite having resources to help them understand the features, in the form of self learning tutorials and video resources, the pre-service teachers found it exasperating and confusing to look for templates and resources in the software. $62 \%$ of the teams indicated that they were unfamiliar with the board and so needed time to explore the board:

Initially, we did not know what the icons meant, so we had trouble navigating the software.

We could not understand certain functions when we applied the features for the first time.

The main problem is the difficulties to understand the instructions of the software.

We were unfamiliar with the layout of the IWB software. Therefore, we spend quite some time trying to figure how to manipulate the respective tools that we needed.

In addition, the pre-service teachers had problems exploring, evaluating and selecting relevant templates for their use. They either could not find them or they were not sure which template was suitable and whether it had a particular pedagogical purpose:

We are not sure which template to use for our activity. The software should give a brief description on the templates.

Classification of templates and other resources confusing...

The templates and pictures are all in the same folder, thus it is hard to locate.

Not sure where to find the templates we need ... Took us a while to navigate around.

We are unsure of certain functions and where to find and edit the templates seen in the 'Examples' folder.

Through analysis of the team reflections, it appeared that some form of skills training for the IWB prior to Lesson 1 (see Figure 1) would be beneficial to alleviate the frustrations pre-service teachers faced when learning how to use the IWB. As majority of them were unfamiliar with the IWB, they may have needed structured teaching of the IWB features before they were asked to do independent exploration. This would have freed time for them to pay more attention to pedagogical approaches (Crison, Lerman \& Winbourne, 2007; Hodge \& Anderson, 2007). In comparison, the 
instructional approaches used in Lesson 2 and Lesson 3 appeared to work more effectively. Pre-service teachers found peer sharing to be useful (Miller \& Glover, 2007). The design of the IWB lessons in teams also helped them alleviate some of the apprehension associated with manipulating a new technology. Therefore, it is evident that more time needs to be spent on providing the pre-service teachers with skills training and thereafter, introducing the lesson resources data base for them to explore lesson ideas created and shared by teachers. This might have reduced their confusion and enabled them to focus on applying what they have learnt to their subject area.

\section{Modifications to the IWB teaching approach}

By examining the factors elicited from the reflections, the researchers are able to address research question 3, which is to ascertain whether the approach adopted for the learning of the new technology effective or is there a need to modify the approach. It is evident that the approach needs to be modified based on the factors which emerged from the pre-service teachers' reflections. The researchers are thus proposing a modified approach and this is currently being implemented for the new cohort of pre-service teachers (Figure 4).

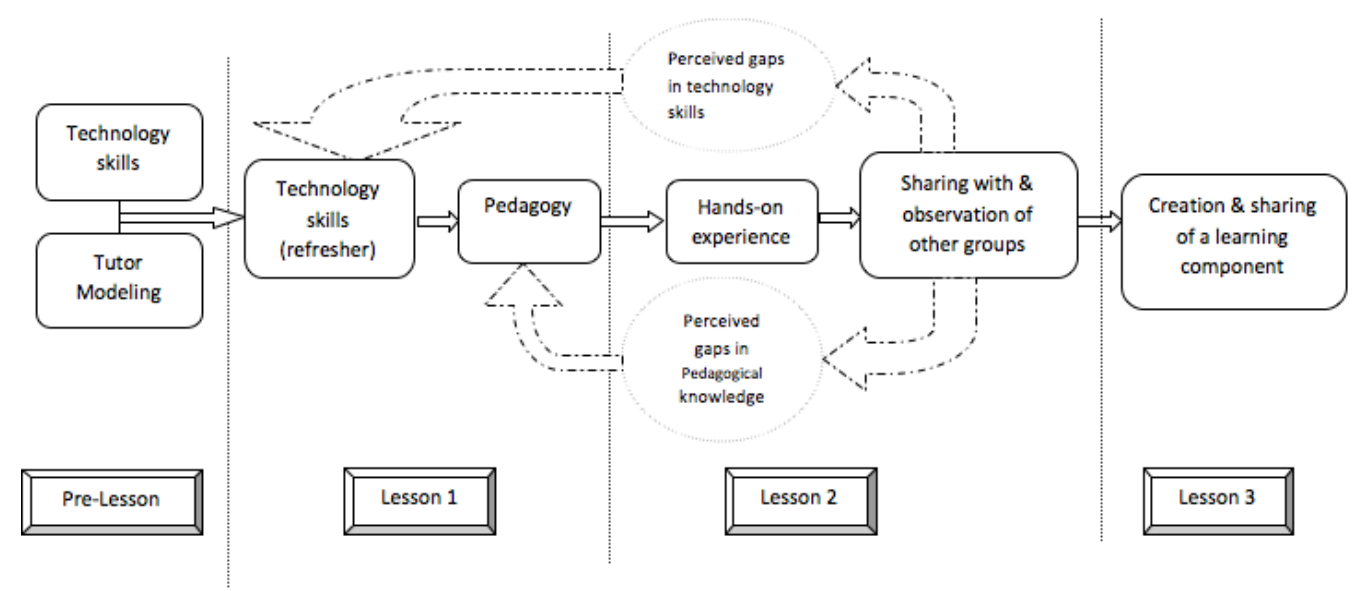

Figure 4: Modified approach to the IWB learning component

\section{Pre-IWB learning component: Skills training for the IWB}

In the modified approach, the intention is to allow the students to have more exposure to skills learning. Hence, the current cohort of pre-service teachers will undergo a twohalf day skills training program to learn technical skills for the IWB prior to attending the ICT core module.

\section{Lesson 1: Refresher on skills training and exposure to pedagogical approaches (subject specific)}

When the students attend the first session, they will be provided a refresher on the basic skills of the IWB. Once they are comfortable, they will be given access to the database where they will be guided to source for ideas by subject. This will address the issues that pre-service teachers raised about not being familiar with the features of the 
board and software. It will also minimise their confusion about what pedagogical approaches they should consider once they are guided where to look for the resources in the database. With technical training conducted prior to the actual lesson, it frees up more time for the tutors to concentrate on the pedagogical approaches of using the IWB for teaching and learning purposes. Since the pre-service teachers found sharing with peers and learning from other teams extremely useful, the researchers will create more opportunities for them to share, thereby creating a culture of sharing.

\section{Conclusion}

In this study, the effectiveness of the IWB technology integration module was assessed through an analysis of the perceptions and learning processes of 124 pre-service teachers' who attended the module. This module taught pre-service teachers the pedagogical uses of the IWB through a combination of tutor modeling, self-paced exploration, peer sharing, and team based design work. Analysis of students' end of course reflections showed that they were generally enthusiastic and receptive towards using the IWB as part of their repertoire of ICT tools. They felt that the IWB best supported frontal teaching by making it more interactive, interesting, and participative for children. However, the type of board used in this study was not effective for supporting collaborative learning as it only allowed a single source of touch input at any point in time.

An analysis of their learning processes showed that besides faculty modeling and opportunities for hands on practice, learning a new technology in teams was also important. Team support was crucial in helping them work through technical difficulties associated with learning a new technology. However, self paced learning of technical skills for the IWB appeared to frustrate pre-service teachers as they generally appreciated more structured forms of technical instruction. The researchers proposed a refined the IWB instruction approach, which can form the basis of future explorations on effective teaching and learning with the IWB amongst Singapore teachers. It is not the technology that matters in the classroom; it is the teachers who conceptualise and design lessons to enhance the students' learning experience (Taber, 2003; Wood \& Ashfield, 2008). Future research should focus on not only teachers learning in school but also how pre-service teachers can be inducted into the learning of new technologies.

\section{References}

Albalat, J. Q. i. \& Tarrago, F. R. (1995). Interpreting internal school factors on the educational integration of IT. In D. Watson \& D. Tinsley (Eds.), Integrating information technology into education. UK, London: Chapman \& Hall.

Ball, B. (2003). Teaching and learning mathematics with an interactive whiteboard. Micromath, 19(1), 4-7. http:/ / www.atm.org.uk/journal/micromath/mm191ball.pdf

Beyerbach, B., Walsh, C. \& Vannatta, R. (2001). From teaching technology to using technology to enhance student learning: Preservice teachers' changing perceptions of technology infusion. Journal of Technology and Teacher Education, 9(1), 105-127.

Blase, J. \& Blase, J. (1999). Principals' instructional leadership and teacher development: Teachers' perspectives. Educational Adminstration Quarterly, 35(3), 349-378.

Braak, J. v. (2001). Individual characteristics influencing teachers' class use of computers. Journal of Educational Computing Research, 25(2), 141-157. 
Brush, T., Glazewiski, K., Rutowiski, K., Berg, K., Stromfors, C., Van-Nest, M. H., Stock, L. \& Stutton, J. (2003). Integrating technology in a field-based teacher training program: The PT3@ASU project. Educational Technology Research and Development, 51(1), 57-72.

Chu, J. L. (2000). Assessment of the integration of technology into the curriculum by middle and high school teachers. Unpublished EdD, Pepperdine University.

Coupal, L. V. (2004). Constructivist learning theory and human capital theory: Shifting political and educational frameworks for teachers' ICT professional development. British Journal of Educational Technology, 35(5), 587-596.

Crison, C., Lerman, S. \& Winbourne, P. (2007). Mathematics and ICT: A framework for conceptualising secondary school mathematics teachers' classroom practices. Technology, Pedagogy and Education, 16(1), 21-39.

Davis, N., Preston, C., \& Sahin, I. (2009). Training teachers to use new technologies impacts multiple ecologies: Evidence from a national initiative. British Journal of Educational Technology, 40(5), 861-878.

Demetriadis, S., Barbas, A., Molohides, A., Palaigeorgiou, G., Psillos, D., Vlahavas, I., et al. (2003). Cultures in negotiation: Teachers acceptance/resistance attitudes considering the infusion of teachnology into schools. Computers $\mathcal{E}$ Education, 41, 19-37.

Ertmer, P. A. (1999). Addressing first- and second-order barriers to change: Strategies for Technology Integration. Educational Technology Research \& Development, 47(4), 47-61.

Flanagan, L. \& Jacobsen, M. (2003). Technology leadership for the twenty-first century principal. Journal of Educational Administration, 41(2), 124-142.

Gillen, J., Staarman, J. K., Littleton, K., Mercer, N. \& Twiner, A. (2007). A 'learning revolution'? Investigating pedagogic practice around interactive whiteboards in British primary classrooms. Learning, Media and Technology, 32(3), 243-256.

Guskey, T. R. (2002). Does it make a difference? Evaluating professional development. Educational Leadership, 59(6), 45-51.

Haldane, M. (2007). Interactivity and the digital whiteboard: Weaving the fabric of learning. Learning, Media and Technology, 32(3), 257-270.

Handler, M. G. (1993). Preparing new teachers to use computer technology: Perceptions and suggestions for teacher educators. Computers $\mathcal{E}$ Education, 20(2), 147-156.

Hodge, S. \& Anderson, B. (2007). Teaching and learning with an interactive whiteboard: A teacher's journey. Learning, Media and Technology, 32(3), 271-282.

Hodgson, B. R. (1995). The roles and needs of mathematics teachers using IT. In D. Watson \& D. Tinsley (Eds.), Integrating information technology into education (pp. 27-37). London: Chapman \& Hall.

Holmes, K. (2009). Planning to teach with digital tools: Introducing the interactive whiteboard to pre-service secondary mathematics teachers. Australasian Journal of Educational Technology, 25(3), 351-365. http: / / www.ascilite.org.au/ajet/ajet25/holmes.html

Jaber, W. E. \& Moore, D. M. (1999). A survey of factors which influence teachers' use of computer-based technology. International Journal of Instructional Media, 26(3), 253-266. [thesis version verified 14 Jun 2010 at http:/ / scholar.lib.vt.edu/theses/available/ etd-7199702347/unrestricted/WJABER2.PDF] 
Jacobsen, D. M. (2001). Building different bridges: Technology integration, engaged student learning, and new approaches to professional development. Paper presented at the 82nd Annual Meeting of the American Educational Research Association, Seattle, Washington. [verified 14 Jun 2010] http:/ / www.eric.ed.gov:80/ERICWebPortal/contentdelivery/servlet / ERICServlet?accno=ED453232

Jacobsen, D. M. (2002). Building different bridges two: A case study of transformative professional development for student learning with technology. Paper presented at the 83rd Annual Meeting of the American Educational Research Association, New Orleans, Louisiana. [verified 14 Jun 2010] http:/ / people.ucalgary.ca/ dmjacobs/aera/building_bridges_two.html

Jewitt, C., Moss, G. \& Cardini, A. (2007). Pace, interactivity and multimodality in teachers' design of texts for interactive whiteboards in the secondary classroom. Learning, Media and Technology, 32(3), 303-317.

Kennewell, S. (2005). Researching the influence of interactive presentation tools on teacher pedagogy. Paper presented at the British Educational Research Association Conference. http: / / www.leeds.ac.uk/educol/ documents/151717.doc

Kennewell, S. \& Beauchamp, G. (2007). The features of interactive whiteboards and their influence on learning. Learning, Media and Technology, 32(3), 227-241.

Knight, P., Pennant, J. \& Piggott, J. (2004). What does it mean to 'use the interactive whiteboard' in the daily mathematics lesson? Micromath, 20(2), 14-16.

López, O. S. (2010). The digital learning classroom: Improving English language learners' academic success in mathematics and reading using interactive whiteboard technology. Computers \& Education, 54, 901-915.

Manternach-Wigans, L. K. (1999). Computer technology integration in Iowa high schools: Perceptions of teachers. Unpublished Doctoral Dissertation, Iowa State University, Iowa. [verified 14 Jun 2010; 11.5 MB] http:/ / www.eric.ed.gov:80/ERICDocs/ data/ericdocs2sql/ content_ storage_01/0000019b/80/16/09/ae.pdf

Martin, W. B. (2000). Learning from the Colwell school: An ethnographic case study of an educational technology culture. Unpublished PhD, Cornell University.

Miller, D. (2003). Developing interactive whiteboard activity. Micromath, 19(33-35).

Miller, D. \& Glover, D. (2007). Into the unknown: the professional development induction experience of secondary mathematics teachers using interactive whiteboard technology. Learning, Media and Technology, 32(3), 319-331.

Pellegrino, J. W. \& Altman, J. E. (1997). Information technology and teacher preparation: Some critical issues and illustrative solutions. Peabody Journal of Education, 72(1), 89-121.

Pierson, M. E. (2001). Technology integration practice as a function of pedagogical expertise. Journal of Research on Computing in Education, 33(4), 413-430.

Polyzou, A. (2005). Growth in teachers' knowledge while learning to teach with multimedia: What has been learned from concrete educational experiences? Technology, Pedagogy and Education, 14(2), 205-223.

Pope, M., Hare, D. \& Howard, E. (2005). Technology integration: Closing the gap between what preservice teachers are taught to do and what they can do. Journal of Technology and Teacher Education, 10(2), 191-203.

Prain, V. \& Hand, B. (2003). Using new technologies for learning: A case study of a whole-school approach. Journal of Research on Technology in Education, 35(4), 441-458. 
Shuldman, M. (2004). Superintendent conceptions of institutional conditions that impact teacher technology integration. Journal of Research on Technology in Education, 36(4), 319-343.

Smith, H., Higgins, S., Wall, K. \& Miller, J. (2005). Interactive whiteboards: Boon or bandwagon? A critical review of literature. Journal of Computer Assisted Learning, 21, 91-101.

Snider, S. L. (2002). Exploring technology integration in a field-based teacher education program: Implementation efforts and findings. Journal of Research on Technology in Education, 34(3), 230-249.

Soetaert, R. \& van Belle, G. C. J. (2001). Breakdown into the virtual user-involved design and learning. Journal of Technology and Teacher Education, 9(1), 31-42. [conference version verified 14 Jun 2010 at http:/ / www.eric.ed.gov:80/ERICWebPortal/ contentdelivery / servlet/ ERICServlet?accno=ED421147]

Solvie, P. A. (2004). The digital whiteboard: A tool in early literacy instruction. The Reading Teacher, 57(5).

Strudler, N. B. \& Wetzel, K. (1999). Lessons from exemplary colleges of education: Factors affecting technology integration in preservice programs. Educational Technology Research $\mathcal{E}$ Development, 47(4), 63-81.

Taber, K. S. (2003). Responding to alternative conceptions in the classroom. School Science Review, 84(308), 84-108.

Venezky, R. L. (2004). Technology in the classroom: Steps toward a new vision. Education, Communication and Information, 4(1), 3-21.

Wang, P. \& Chan, P. S. (1995). Advantages, disadvantages, facilitators and inhibitors of computer-aided instruction in Singapore's secondary schools. Computers \& Education, 25(3), 151-162.

Wood, R. \& Ashfield, J. (2008). The use of interactive whiteboard for creative teaching and leanring in literacy and mathematics: A case study. British Journal of Educational Technology, 39(1), 84-96.

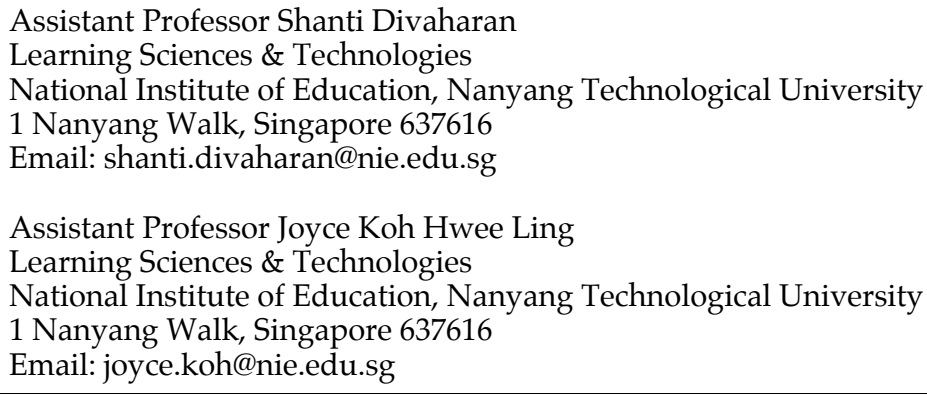

